\title{
Understanding Context in Learning- centred Approaches to Climate Change Communication
}

\author{
Blane Harvey, Liz Carlile, Jonathan Ensor, Ben Garside and \\ Zachary Patterson
}

\begin{abstract}
Communication on climate change research has long been dominated by top-down delivery of information aimed at informing on future climate scenarios and climate-related events. However, emphasis in this field is slowly shifting to more process-oriented approaches to communication, and the need to integrate learning is receiving increasing attention. This article argues that despite the challenges in shifting research communication on climate change into a more dialogical and learning-oriented model of practice, the realities faced by communities impacted on the ground make this shift imperative. Drawing on recent research, we consider how the context in which initiatives seek to engage in research communication will and should influence what is possible and what is desirable through these new approaches. We reflect on how efforts to understand context in one particular case served to shape a communication strategy from its outset, and note the opportunities and challenges revealed through this process. We then conclude by highlighting how climate change has reinforced arguments in favour of a focus of inclusive learning processes in communication for development.
\end{abstract}

\section{Introduction}

The communication of research and information on climate change, particularly in the context of development, is notable for engaging a wide range of complexities and challenges. Some of these are shared by other development priorities, and others are relatively unique. Three areas that we see as particularly significant and challenging are: the nature and impacts of climate change itself; the range and availability of knowledge needed to adequately respond to it; and the cross-scalar nature of climate change impacts and responses. All of these areas are in turn shaped by the political, institutional, social, and environmental contexts in which climate impacts are experienced and communication must be carried out. Together these will fundamentally shape the range of options that communities, researchers, practitioners and decision-makers have at their disposal to take informed and meaningful action. In this article we describe how recent shifts in thinking around communication on climate change and development have sought to address these challenges, and reflect on key factors that enable or constrain these shifts.

In the first section we introduce these areas of complexity in responding to climate change in greater detail and examine how they have typically figured in communication in the global South, particularly in helping communities to adapt to the current and projected impacts of climate change. We then look at how understandings of how climate change should be communicated within this context and consider how the concept of social learning has emerged as an approach to dialogical (two-way) communication that aims to overcome some of the constraints we have noted. In the second section we look at efforts to promote new approaches to communication and social learning within the Climate Change Agriculture and Food Security programme (CCAFS) of the

Consultative Group on International Agricultural Research (CGIAR) consortium. In particular, we

IDS Bulletin Volume 43 Number 5 September 2012 @ 2012 The Authors. IDS Bulletin @ 2012 Institute of Development Studies Published by Blackwell Publishing Ltd, 9600 Garsington Road, Oxford OX4 2DQ, UK and 350 Main Street, Malden, MA 02148, USA 
draw attention to the context within which this initiative seeks to support communication and learning for informed action on climate change and describe how contextual factors within the CGIAR system and in the regions where CGAFS is working have shaped the possible actions that the programme might pursue. We conclude by reflecting on the lessons learned from these processes and recommendations on how they can inform other initiatives.

\subsection{Communicating climate change in the context of development: background and challenges}

Early approaches to communicating climate change were relatively narrowly focused on scientific findings and synthesis reports, and were often prompted by extreme weather events or high-level conferences and policy meetings (Moser 2010). However, there has been a shift in climate change communication over the past decade, as studies have shown that communication must move beyond simply providing information to include raising awareness and promoting active public engagement (Russill and Nyssa 2009; Moser and Dilling 2007). This move beyond information sharing was influenced in large part by communicators taking climate change research and discourse out of the isolated spheres of science and policy, and opening up the discussion of climate to other audiences, forums and scales of action.

In the context of the global South, particularly Africa, where the impacts of climate change are expected to be pronounced and are already affecting people's livelihoods (Challinor et al. 2007), resources for addressing climate change are limited - even basic dissemination approaches aimed at informing individuals have had limited uptake outside of more specialised development communication channels. The importance of a shift away from these early models, which relied heavily on decontextualised content relayed from outside media sources (largely from the North), is noted in the conclusions of a major BBC World Service Trust Study:

The information flow on climate change to date has principally been from the rest of the world to Africa. It needs to be replaced by a sustained dialogue and two-way flow of information that empowers African citizens and ensures publics and politicians in countries mainly responsible for causing climate change are better informed of African realities and perspectives (BBC World Service Trust 2009: 2).

Such a shift, however, raises important challenges that researchers, practitioners, media and knowledge intermediaries must confront in order to effectively engage. These relate to both the content of what can be communicated on the nature and impacts of climate change; and to the social, institutional and cultural barriers of how this communication and exchange can take place.

In terms of what can be communicated, challenges are linked to the complex and uncertain nature of long-term climate change globally, the limited availability and variable quality of scientific climate data in many developing countries, as well as the marginalisation of local and traditional climate knowledge held by communities. The barriers to communication and exchange in the South, on the other hand, are linked to the absence of appropriate forums and methods for exchange, failure to translate technical information into useable formats, challenges to access among communities including illiteracy and the digital divide, as well as constraints in terms of capacity and incentive structures within the media, government, research institutions and other key knowledge intermediaries (Harvey et al. forthcoming). While investment in improving the tools, capacities and strategies for communicating climate change research and knowledge will help to address many of these challenges, a number of others are not likely to be resolved before communities will need to make fundamental decisions to respond to climate impacts. Still others - such as the complex and uncertain nature of climate change - may never be completely addressed.

The challenges highlighted above, paired with growing recognition of the role that local (or endogenous) knowledge must have in effectively responding to climate change in uncertain and highly context-driven situations, and the centrality of dialogue and reflection (using language and concepts drawn from the communities themselves), have led to a strong emphasis on iterative learning processes as both a means and an end of communication. Social learning in particular has received attention as an approach to tackling the complex problem of 
human-induced climate change (Ensor 2011; Collins and Ison 2009; Pahl-Wostl et al. 2008). Defined in this context as 'the collective action and reflection that takes place amongst both individuals and groups when they work to improve the management of the interrelationships between social and ecological systems' (Keen et al. 2005: 4), social learning is inherently communicative and goes beyond linear information transmission to deliberation aimed at behavioural and social change (Reed et al. 2010).

Yet challenges remain in terms of harnessing the potential of social learning in practice, in particular in addressing power inequalities between actors in social learning processes (Armitage et al. 2011) and in ensuring that shared learning emerges from multi-stakeholder meetings (Cundill and Fabricius 2009).

Particularly in Africa, Tschakert and Dietrich (2010: 11) note that 'our existing methodological toolbox is sparsely equipped to facilitate and sustain such adaptive and anticipatory learning in the face of complex risks and uncertainties.' Both research institutions and policy bodies have struggled to effectively broker learning and coordination across scales in ways that can bring research into closer dialogue with local experience and policy processes. In sum, Armitage et al. suggest that:

Greater attention is needed to capacitybuilding, recognition of the role of risk, and consideration of how incentives could be used to encourage learning. Further consideration of the role of power and marginality among groups participating in the learning process is also needed, as is more systematic evaluation to monitor and measure learning outcomes (2008: 86).

The shift from linear and didactic models of research communication discussed here is one which many organisations working at the intersection of climate and development are now beginning to explore, and in doing so are revealing the challenges and opportunities that these approaches present. Among them is the recently established Climate Change Agriculture and Food Security programme of the GGIAR. In the next section, we look more closely at how this programme's decision to adopt a social learning approach to communicating climate change research has led to reflection on the institutional context within which CGAFS sits and the broader range of existing initiatives with which the programme can engage. This reflection draws upon research we conducted on behalf of CCAFS in 2012 (Harvey et al. forthcoming) and a subsequent workshop for key stakeholders and potential CCAFS partners hosted by CGAFS in May 2012.' Drawing on the points raised by Armitage et al. (2008) above, we consider how incentives, capacity, power, and other factors within and outside of the initiative both constrain and provide opportunities for action.

\section{Context is key - communicating climate} research through social learning at CCAFS

With an annual research budget of over US\$600 million and close to 1,000 scientific researcher staff from over 50 countries the CGIAR stands as one of the world's most prominent agricultural research institutions (see CGIAR; ${ }^{2}$ McAllister $e t$ al. 2008). Increased productivity for staple crops and farm animals and new rice varieties are just some of the significant contributions made to agricultural research over its 38-year history. CGIAR research, which aims to model future scenarios and develop innovations to tackle global challenges through cutting-edge research, has not traditionally been about directly helping communities address their day-to-day needs. This is a challenge for communicating climate change research for adaptation which, as stated above, depends both on harnessing endogenous knowledge held in communities and on facilitating spaces for dialogue and knowledge co-creation.

As the CCAFS programme aims to shift more toward direct engagement with community priorities alongside broader research needs, questions emerge about the context within which this must take place. To help them explore these questions, CGAFS commissioned us (the authors) to study the landscape of existing initiatives inside the GGIAR system and in the broader field of climate change adaptation in the South (see Harvey et al. forthcoming). The study examined where and how innovative climate change communication and social learning approaches are being used, and how CCAFS might engage to add value or address gaps through its own engagement strategy. In doing so the team was able to reveal some useful points for reflection and action. 


\subsection{Internal challenges: reframing communication and learning within CCAFS}

Clark et al. (2011: 1) suggest that 'the question for scientists, program managers and donors is... not whether but rather how to modify programme design and practice in ways that help to realise the great potential of research programs to support sustainable development.' Indeed CCAFS, one of four programmes cutting across the CGIAR, is going to great lengths to do just that. One of CCAFS sub-objectives specifically identifies linking knowledge to action and is asking itself how it can build a research agenda that reflects its stakeholder's needs as well as changing behaviour inside the system.

But is change possible? Like researchers the world over, the credibility of CGIAR researchers rests on publication in peer-reviewed journals, presentations at conferences, peer-to-peer dialogue and review. Incentive structures, patterns of funding, organisation of time and management are all based on this organising principle. This model of research communication delivers the first of CCAFS engagement and communications' objectives: 'providing a credible and authoritative platform for scientific information, knowledge and tools' but sits in tension with their second objective of 'facilitating user-driven research, science-based dialogue, knowledge sharing, and evidence-based policy among partners at all levels (CCAFS 2011). Without a reflection on how internal incentive systems and hierarchies (such as academic forums being more important sites of engagement than communities) shape the partnerships and feedback loops fundamental to social learning situations, the promotion of such approaches will always sit at the margins of broader activity.

Building on recent research into institutions and the promotion of social learning, we argue that institutions where social learning is fundamental to the internal functioning are better positioned to engage with similar processes in broader networks (Siebenhüner 2006; Reed 2010). Discussions with researchers in the GGIAR consortium suggest that there are broadly three profiles of researcher. First are those who consider themselves 'hard scientists' and are focused on the more traditional research projects that they have fought hard to win funding for. They are less concerned about what they see as innovative communication initiatives and more concerned on 'getting the climate models right'. The second group, we suggest, are generally supportive of new research communication and engagement approaches but do not see themselves actually engaging in the processes. They do, however see the value of their work being used for these ends. The third group are those who support the principle of a more dialogic and learning-centred environment sharing research and developing new agendas, and are keen to engage with these processes.

Many of the researchers in the CGAFS team fall into this small third group interested in building a community of practice on social learning. They see themselves as the committed leaders and, with external partners, the change agents, and are currently strategising how best to achieve these aims. However, the challenges to doing so include influencing and incentivising a shift in behaviour to orientate scientists into more engaged models of practice, particularly as a minority voice within the CGIAR system. There is also reluctance among many researchers within the system to engage in yet another re-orientation of their work strategies and incentive structures when they have only recently undertaken major institutional reform. ${ }^{3}$ At the same time the comparatively long-term nature of CCAFS' funding (ten years), the formalisation of social learning aims into their programming, and the presence of 'champions' of learning within the programme offer opportunities in the context of the CGAFS programme.

\subsection{Understanding and creating an enabling environment for change outside the system}

We recognise the scope of the challenge for CGAFS to build a community of practice on social learning inside the CGIAR system and to win the confidence and support of other researchers and their donors. However, there are also some critical external-facing challenges to embrace if the team take on a strategic leadership role. It is clear that a social learning approach to communicating research and engaging with communities is not something that CGIAR can pursue alone, but rather they should be linking their research agenda to other models of knowledge production. To do so they must work in partnership with a range of other stakeholders across scales, from community-level institutions to facilitating non-governmental 
organisations (NGOs), practitioners, and the private sector in alliances that can work together over time (Cash et al. 2006; Patt et al. 2007). Our analysis of existing CCAFS programming revealed several strong examples that demonstrate this kind of approach already being put into practice. ${ }^{4}$ At a recent strategy workshop on social learning and communication at CGAFS a representative from the Swiss Agency for Development and Cooperation urged that 'complexity is only grasped when we $d o$ things [and do them] in a reflective way' (Flury pers. comm. 2012). CCAFS is in a position to identify and champion and support partnerships and alliances that can 'do' together.

In this vein, the study revealed notable trends in the existing range of initiatives through which CCAFS might pursue partnerships. First, there are already a number of initiatives being implemented using learning-centred approaches to address climate change at local levels in the South. However, these approaches still represent a small minority (14 per cent of all initiatives reviewed), and many of them are operating at small scales with very limited and short-term funding, often with weak links to broader initiatives. Further, even when local communities are the stated beneficiaries, local languages are often overlooked, and there is a greater emphasis on facilitation and knowledge brokerage at the level of the informed professionals than at the community level. As a community of practice on climate and development, it seems we are often speaking to ourselves, about ourselves and for ourselves. Finally, the study highlights the need to look closely at the balance of emphasis between technological innovation and methodological innovation. At the community scale there are tried and tested communication technologies that are proven to be effective in engaging audiences - community radio stands as one example. However, initiatives often fail to tap into these established technologies and modes of communication. At the same time, the role of innovative methodologies for facilitating social learning and two-way communication between stakeholders is often underemphasised in favour of technologies.

Our review of this external context also suggested important spaces and opportunities to intervene. For example, CGAFS has access to major donors and can play an influencing role in sharing knowledge and experience on a social learning approach that can bring great gains in promoting community resilience and adaptive capacity. It can also use this strategic strength to engage, sustain and expand the reach of existing social learning initiatives across scales, linking them through the CGIAR's consortium of regional centres and initiatives. It can also use this vast research network to deepen our collective understanding on the effectiveness of these communication strategies on a more global scale.

\section{Discussion and conclusions}

This article has sought to contribute empirical evidence drawn from one organisation's efforts to introduce social learning into its communication and research strategies. The shift toward more dialogical and learning-oriented models of research communication is essential for successful action on climate change but cannot be undertaken in a vacuum, regardless of how large or well-funded an initiative. There is always a need to look inside the institution itself to see where the opportunities and barriers might lie, and outside into the broader context where one hopes to effect change, in order to understand the alliances that can be forged, the constraints that must be overcome, and one's own positionality as an intervening force. The complexity, uncertainty and unpredictability of climate change means that we must work together across communities, nations and regions. We have to 'do' together to learn how to adapt, and we must bridge the local knowledge from centuries of community innovation with the findings and future modelling brought to us by sophisticated research programmes.

CCAFS' approach to engagement has been one of seeing what already exists, and of convening a community of well-placed actors, learning from them and understanding the context in which they hope to initiate their work. This demonstrates a way of operating that is highly conducive to social learning, with a clear focus on a process that enables dialogue, rather than a prior commitment to particular outcomes. This ability to see the process of engagement as the outcome is a defining characteristic of the current shift towards a more dialogical, learningcentred model of development communication and climate change adaptation. But can this shift be sustained over time? 
Understanding how a large, amorphous organisational construction like the 15 global GGIAR centres could move from a model focused on communicating the science of climate change toward one based on social learning is extremely useful in better understanding how to move towards large-scale engagement for climate change adaptation. The CCAFS research theme has an energy and commitment to make this change. If it can work both inside the organisation and outside to create new partnerships and to share its experience in order to influence new ways of working and more sympathetic donor support, then change can happen. For such change to be sustainable implies that we all take responsibility to learn together within our own organisations. We must ask ourselves whether we are preaching to the same old target audiences - who, for the most part, are the already converted. Are we really listening to where we can find opportunities to

\section{Notes}

1 See http://commsl4climate.wikispaces.com/ (accessed 25 June 2012).

2 'Our research accounted for US\$673 million or just over 10 percent of the US $\$ 5.1$ billion spent on agricultural research for development in 2010' (Who We Are, www.cgiar.org/who-we-are/ accessed 27 June 2012).

3 See www.cgiar.org/who-we-are/history-ofcgiar/cgiar-reform/ (accessed 27 June 2012).

\section{References}

Armitage, D.; Marschke, M. and Plummer, R. (2008) 'Adaptive Co-management and the Paradox of Learning', Global Environmental Change 18.1: 86-98

Armitage, D.; Berkes, F.; Dale, A.; KochoSchellenberg, E. and Patton, E. (2011) 'Comanagement and the Co-production of Knowledge: Learning to Adapt in Canada's Arctic', Global Environmental Change 21.3: 995-1004

BBC World Service Trust (2009) 'Least Responsible, Most Affected, Least Informed: Public Understanding of Climate Change in Africa', Policy Briefing 3, London: BBC World Service Trust

Cash, D.W.; Adger, W.N.; Berkes, F.; Garden, P.; Lebel, L.; Olsson, P.; Pritchard, L. and Young, O. (2006) 'Scale and Cross-Scale Dynamics: Governance and Information in a Multilevel World', Ecology and Society 11.2: 8 learn together and recognising that the process, or journey, might in itself be a key outcome?

Building support for social learning also means investing in reflection and lesson sharing between development practitioners. There are many examples of learning-based practice to be found among a diverse pool of small and larger scale climate change communication initiatives. More evidence on exactly how these innovative approaches are producing new value needs to be coupled with forums that enable learning to emerge between those involved in similar social change actions. In other words, we need to develop strategies and opportunities for learning about learning. Perhaps unsurprisingly, what matters most here is a focus on process. In finding a way through the shifting and uncertain terrain of climate change, it is necessary to step back from our assumptions of what works best and increasingly trust in shared, emergent outcomes.

4 Notable CCAFS initiatives using strong partnership or cross-scale collaboration approaches to research and communication include Regional Socio Economic Scenarios, Climate Analogues, Coffee Under Pressure, and the Index Based Livestock Insurance project.

CCAFS (2011) Engagement and Communications Strategy, Nairobi: Climate Change Agriculture and Food Security

Challinor, A.; Wheeler, T.; Garforth, C.; Craufurd, P. and Kassam, A. (2007) 'Assessing the Vulnerability of Food Crop Systems in Africa to Climate Change', Climatic Change 83.3: 381-99

Glark, W.G.; Tomich, T.P.; van Noordwijk, M.; Guston, D.; Catacutan, D.; Dickson, N.M. and McNie, E. (2011) Boundary Work for Sustainable Development: Natural Resource Management at the Consultative Group on International Agricultural Research (CGIAR), PNAS early edition, http:/www.pnas.org/content/early/2011/08/11/ 0900231108.abstract (accessed 25 June 2012)

Collins, K. and Ison, R. (2009) 'Living with Environmental Change: Adaption as Social Learning', Environmental Policy and Learning 19.6: $351-7$ 
Cundill, G. and Fabricius, C. (2009) 'Monitoring in Adaptive Co-management: Toward a Learning Based Approach', Journal of Environmental Management 90.11: 3205-11

Ensor, J. (2011) Uncertain Futures: Adapting Development to a Changing Climate, Rugby: Practical Action Publishing

Harvey, B.; Carlile, L.; Ensor, J.; Garside, B.; Patterson, Z. and Naess, L.O. (forthcoming) Climate Change Communication and Social Learning: A Review of Needs and Options, CCAFS Working Paper, Nairobi: Consultative Group on International Agricultural Research

Keen, M.; Brown, V.A. and Dyball, R. (2005) Social Learning in Environmental Management: Towards a Sustainable Future, London: Earthscan

McAllister, E. et al. (2008) Bringing Together the Best of Science and the Best of Development: Independent Review of the CGIAR System Technical Report, CGIAR: 103, 105, www.cgiar.org/www-archive/ www.cgiar.org/pdf/agm08/agm08_CGIARtechnical-report.pdf (accessed 27 June 2012)

Moser, S. (2010) 'Communicating Climate Change: History, Challenges, Process, and Future Direction', WIREs Climate Change 1, January/February
Moser, S. and Dilling, L. (2007) Creating a Climate for Change: Communicating Climate Change and Facilitating Social Change, New York: Cambridge University Press

Pahl-Wostl, C.; Tabara, D.; Bouwen, R.; Craps, M.; Dewulf, A.; Mostert, E.; Ridder, D. and Taillieu, T. (2008) 'The Importance of Social Learning and Culture for Sustainable Water Management', Ecological Economics 64.3: 484-95

Patt, A.; Ogallo, L. and Hellmuth, M.(2007) 'Learning from 10 Years of Climate Outlook Forums in Africa', Science 318: 49-50

Reed, M. et al. (2010) 'What is Social Learning?', Ecology and Society

Russill, C. and Nyssa, Z. (2009) 'The Tipping Point in Climate Change Communication', Global Environmental Change 19: 336-44

Siebenhüner, B. (2006) Social Learning in the Field of Climate Change, http://biogov.cpdr.ucl.ac.be/ bioinstit/papers/SIEBENHUENER_paper.pdf (accessed 11 June 2012)

Tschakert, P. and Dietrich, K.A. (2010) 'Anticipatory Learning for Climate Change Adaptation and Resilience', Ecology and Society 15.2: 11 